\section{KLK1 Gene Polymorphisms Are Not Associated with Lupus Nephritis in a Chinese Han Population}

\section{To the Editor:}

Lupus nephritis (LN) is one of the most serious manifestations of systemic lupus erythematosus (SLE) and is an important predictor of poor outcome ${ }^{1}$. Susceptibility to LN is the end result of complex interactions between polymorphic genetic factors involved in the regulation of immune responses. However, to date, a clear etiology is still obscure. Recently, it was reported that kallikrein genes, especially $K L K 1$ gene, were associated with $\mathrm{LN}$ in mice and in Caucasians. However, such an association was not shown in all the investigated populations ${ }^{2,3}$. This implies that different genetic influences exist in different ethnic groups ${ }^{2-5}$, and it was decided to further validate the association of $K L K 1$ gene polymorphisms with $\mathrm{LN}$ in a Chinese Han population.

A case-control association study was performed on $306 \mathrm{LN}$ patients (age $32.2 \pm 11.1 \mathrm{yrs}, 84.2 \%$ female) and 338 matched healthy controls (age $31.7 \pm 9.1 \mathrm{yrs}, 55.8 \%$ female). $\mathrm{LN}$ patients were recruited from Peking University First Hospital; all were of Han ethnicity living in northern China and met revised SLE criteria of the American College of Rheumatology $\mathrm{y}^{6,7}$. LN was confirmed by renal biopsy (including 28, 64, 156, and 58 cases of class II, III, IV, V, respectively) according to the revised 2003 International Society of Nephrology/Renal Pathology Society classification system. Controls were geographically and ethnically matched. All samples were independent. Three tagging single-nucleotide polymorphisms were detected, including rs5516 (Gln145Glu, exon 3) and rs5517 (Glu186Lys, exon 4), which could efficiently tag 8 SNP (minor allele frequency $>0.1$, from the 5 ' flanking sequence $1.5 \mathrm{~kb}$ upstream to the 3 ' flanking region) of the $K L K 1$ gene, with $\mathrm{r}^{2}>90 \%$ for both common haplotype and unmeasured variants of the $K L K 1$ gene, based on the HapMap data of Han Chinese in a Beijing population ${ }^{8}$. rs5516 and rs2740502 (intron 1) were formerly reported to be associated with $\mathrm{LN}$ in Caucasians ${ }^{2}$. Our study was approved by the medical ethics committee of Peking University. All patients gave informed consent.

The overall 3 tSNP were genotyped by TaqMan allele discrimination assays (Assay ID: C_2932109_10 for rs2740502, C_2932115_20 for rs5517, and C_8705506_1_for rs5516; Applied Biosystems, Foster City, CA, USA) according to the manufacturer's instructions. Concordance was checked against $5 \%$ samples and reached $100 \%$. Disease associations were analyzed by chi-square tests using $2 \times 2$ as well as $2 \times 3$ contingency tables. Linkage disequilibrium (LD) was tested using Haploview (version 3.32, http://www.broad.mit.edu/mpg/haploview). Haplo.Stats software (version 1.4.3, http://cran.r-project.org/web/packages/haplo.stats) was used to test the association of statistically inferred haplotypes with LN. Power of the study was calculated by Power and Sample Size Calculations Software (version 3.0, http://biostat.mc.vanderbilt.edu/PowerSampleSize). Deviation from Hardy-Weinberg equilibrium was not observed for any of the SNP in the control or LN samples ( $\mathrm{p}=0.16$ to 0.96 ). LD analysis in healthy controls revealed that $\mathrm{r}^{2}$ values between rs2740502, rs5516, and rs5517 were 0.05 and 0.32 , respectively. In our case-control study, we had 0.978 (rs2740502), 0.965 (rs5516), and 0.992 (rs5517) power to detect a two-fold increased risk, assuming an $\alpha$-level of 0.05 . Allele type, genotype (Table 1), and haplotype (data not shown) distributions of identified polymorphisms were compared between patients and controls, but none of the 3 tSNP exhibited evidence of an association with susceptibility to LN in this Chinese population $(\mathrm{p}>0.05)$.

The sample of LN in our study was large (306, comparable to $319 \mathrm{LN}$ patients in total described by Liu, et $a l^{2}$ ), homogeneous in ethnicity, proven by biopsy, and all enrolled from a single center; the selected tSNP could efficiently tag common alleles of $K L K 1$ gene, all of which guaranteed reliability. We thus suggest that $K L K 1$ gene is not associated with LN in a Chinese Han population.

The likely reason for the lack of association may be genetic heterogeneity. SLE is more common, more severe, of earlier onset, and has distinct clinical features in East Asians compared with Europeans. These clin-
Table 1. KLK1 polymorphisms in LN patients and healthy controls in Han Chinese. Values are number $(\%)$

\begin{tabular}{|c|c|c|c|}
\hline SNP & Patients, $\mathrm{n}=306$ & Controls, $\mathrm{n}=338$ & $\mathrm{p}$ \\
\hline \multicolumn{4}{|l|}{ rs2740502 } \\
\hline \multicolumn{4}{|l|}{ Genotype frequency } \\
\hline $\mathrm{G} / \mathrm{G}$ & $13(4.2)$ & $20(5.9)$ & \multirow[t]{3}{*}{0.246} \\
\hline $\mathrm{C} / \mathrm{G}$ & $119(38.9)$ & $112(33.1)$ & \\
\hline $\mathrm{C} / \mathrm{C}$ & $174(56.9)$ & $206(60.9)$ & \\
\hline \multicolumn{4}{|l|}{ Allele frequency } \\
\hline $\mathrm{G}($ vs C) & $145(23.7)$ & $152(22.5)$ & 0.607 \\
\hline \multicolumn{4}{|l|}{ Recessive model } \\
\hline $\mathrm{G} / \mathrm{G}(\mathrm{vs} \mathrm{C} / \mathrm{G}+\mathrm{C} / \mathrm{C})$ & $13(4.2)$ & $20(5.9)$ & 0.337 \\
\hline \multicolumn{4}{|l|}{ Dominant model } \\
\hline $\mathrm{G} / \mathrm{G}+\mathrm{C} / \mathrm{G}(\mathrm{vs} \mathrm{C} / \mathrm{C})$ & $132(43.1)$ & $132(39.1)$ & 0.293 \\
\hline \multicolumn{4}{|l|}{ rs 5516} \\
\hline \multicolumn{4}{|l|}{ Genotype frequency } \\
\hline $\mathrm{G} / \mathrm{G}$ & $13(4.2)$ & $8(2.4)$ & \multirow[t]{3}{*}{0.373} \\
\hline $\mathrm{C} / \mathrm{G}$ & $94(30.7)$ & $111(32.8)$ & \\
\hline $\mathrm{C} / \mathrm{C}$ & $199(65.0)$ & $219(64.8)$ & \\
\hline \multicolumn{4}{|l|}{ Allele frequency } \\
\hline $\mathrm{G}(\mathrm{vs} \mathrm{C})$ & $120(19.6)$ & $127(18.8)$ & 0.709 \\
\hline \multicolumn{4}{|l|}{ Recessive model } \\
\hline $\mathrm{G} / \mathrm{G}(\mathrm{vs} \mathrm{C} / \mathrm{G}+\mathrm{C} / \mathrm{C})$ & $13(4.2)$ & $8(2.4)$ & 0.179 \\
\hline \multicolumn{4}{|l|}{ Dominant model } \\
\hline $\mathrm{G} / \mathrm{G}+\mathrm{C} / \mathrm{G}(\mathrm{vs} \mathrm{C} / \mathrm{C})$ & $107(35.0)$ & $119(35.2)$ & 0.949 \\
\hline \multicolumn{4}{|l|}{ rs5517 } \\
\hline \multicolumn{4}{|l|}{ Genotype frequency } \\
\hline $\mathrm{T} / \mathrm{T}$ & $54(17.6)$ & $57(16.9)$ & \multirow[t]{3}{*}{0.471} \\
\hline $\mathrm{C} / \mathrm{T}$ & $159(52.0)$ & $163(48.2)$ & \\
\hline $\mathrm{C} / \mathrm{C}$ & $93(30.4)$ & $118(34.9)$ & \\
\hline \multicolumn{4}{|l|}{ Allele frequency } \\
\hline $\mathrm{T}($ vs C) & $267(43.6)$ & $277(41.0)$ & 0.336 \\
\hline \multicolumn{4}{|l|}{ Recessive model } \\
\hline $\mathrm{T} / \mathrm{T}(\mathrm{vs} \mathrm{C} / \mathrm{T}+\mathrm{C} / \mathrm{C})$ & $54(17.6)$ & $57(16.9)$ & 0.793 \\
\hline \multicolumn{4}{|l|}{ Dominant model } \\
\hline $\mathrm{T} / \mathrm{T}+\mathrm{C} / \mathrm{T}(\mathrm{vs} \mathrm{C} / \mathrm{C})$ & $213(69.6)$ & $220(65.1)$ & 0.222 \\
\hline
\end{tabular}

p values were calculated by chi-square analysis using $2 \times 3$ (comparison of genotype frequencies) or $2 \times 2$ (other comparisons) contingency tables.

ical differences are independent of environment and are likely to be genetically determined, thus it was to be expected that SLE will have different genetic influences in different ethnic groups. This lack of association in our study provides information with respect to investigations for a role of members of the kallikrein system, at least of $K L K 1$, in autoimmune diseases among different populations $s^{2,3,9,10}$. Further study involving rare alleles of $K L K 1$ and polymorphisms within other kallikrein genes will be needed.

XU-JIE ZHOU, PhD; JI-CHENG LV, MD; MING-HUI ZHAO, MD, PhD; HONG ZHANG, MD, PhD, Renal Division, Peking University First Hospital, Peking University Institute of Nephrology and Key Laboratory of Renal Disease, Ministry of Health of China, Beijing, 100034, People's Republic of China.

Supported by grants from the National Natural Science Foundation of China (No. 30801022 and No. 30825021) and the Foundation of Ministry of Health of China (No. 200802052).

Address correspondence to Dr. H. Zhang; E-mail: hongzh@bjmu.edu

\section{REFERENCES}

1. Li T, Carls GS, Panopalis P, Wang S, Gibson TB, Goetzel RZ. Long-term medical costs and resource utilization in systemic lupus erythematosus and lupus nephritis: A five-year analysis of a large 
Medicaid population. Arthritis Rheum 2009;61:755-63.

2. Liu K, Li QZ, Delgado-Vega AM, Abelson AK, Sanchez E, Kelly JA, et al. Kallikrein genes are associated with lupus and glomerular basement membrane-specific antibody-induced nephritis in mice and humans. J Clin Invest 2009;119:911-23.

3. Ponticelli C, Meroni PL. Kallikreins and lupus nephritis. J Clin Invest 2009;119:768-71.

4. Harley IT, Kaufman KM, Langefeld CD, Harley JB, Kelly JA. Genetic susceptibility to SLE: new insights from fine mapping and genome-wide association studies. Nat Rev Genet 2009;10:285-90.

5. Yang W, Zhao M, Hirankarn N, Lau CS, Mok CC, Chan TM, et al. ITGAM is associated with disease susceptibility and renal nephritis of systemic lupus erythematosus in Hong Kong Chinese and Thai. Hum Mol Genet 2009;18:2063-70

6. Tan EM, Cohen AS, Fries JF, Masi AT, McShane DJ, Rothfield NF, et al. The 1982 revised criteria for the classification of systemic lupus erythematosus. Arthritis Rheum 1982;25:1271-7.

7. Hochberg MC. Updating the American College of Rheumatology revised criteria for the classification of systemic lupus erythematosus [letter]. Arthritis Rheum 1997;40:1725.

8. Zhao W, Wang L, Lu X, Yang W, Huang J, Chen S, et al. A coding polymorphism of the kallikrein 1 gene is associated with essential hypertension: a tagging SNP-based association study in a Chinese Han population. J Hypertens 2007;25:1821-7.

9. Li QZ, Zhou J, Yang R, Yan M, Ye Q, Liu K, et al. The lupus-susceptibility gene kallikrein downmodulates antibody-mediated glomerulonephritis. Genes Immun 2009;10:503-8.

10. Cassim B, Shaw OM, Mazur M, Misso NL, Naran A, Langlands DR, et al. Kallikreins, kininogens and kinin receptors on circulating and synovial fluid neutrophils: role in kinin generation in rheumatoid arthritis. Rheumatology 2009;48:490-6.

J Rheumatol 2010;37:6; doi:10.3899/jrheum.091316 